formations are not even confined to be conformal, as in the case $m=1$; so that the theory of harmonic integrals contains, in a sense, a good deal of lumber which must be cleared away before the genuine applications to obtain algebraic-geometric results can be made. The definition of the geometric genus in terms of the signature of an intersection matrix, published some years ago for surfaces and here generalized, is however a triumph which would have justified a far more laborious analysis, even had it been the only result ; and the conditions, in terms of vanishing of periods, for a cycle to be algebraic (that is, to be the image on the Riemannian of some algebraic sub-variety on the original variety), though apparently not completely worked out as regards their sufficiency, look as if they might lead to results of great value. The theory is of course in its infancy, and it is hard to say yet how far it may take us; its chief lack so far, if it is to achieve a comparable power and importance with the classical theory-for curves, seems to be anything like a generalization of Abel's theorem; and it is hard to see what form such a result could be expected to take. The applications to continuous groups seem to consist mainly of new proofs of known results, but here again it is early to say what may be achieved.

The whole book is exceedingly difficult to read -a difficulty which is partly inherent in the subject, but which one feels also is somewhat characteristic of the author. The style is very dry and severe; the summaries of previous work are too brief and formal to be readily understood unless the reader is already fairly familiar with the work in question; little time is spared for pointing out the purpose of the steps taken, or of the definitions introduced; and the notation (which is necessarily very intricate) has not always been selected with 'sufficient care to avoid confusion-thus on p. $160 i$ is in one equation a dunimy suffix over which summation takes place, and the square root of -1 , and there are other pitfalls of the same kind, though less glaring. The printing on the other hand seems admirable, and in all that complicated jungle of formulæ I have not detected one misprint. Patrick DU VaL.

\title{
STEAM, AIR AND GAS POWER
}

\section{Steam, Air and Gas Power}

By Prof. William H. Severns and Prof. Howard E. Degler. Third edition. Pp. vii +511. (New York: John Wiley and Sons, Inc.; London: Chapman and Hall, Ltd., 1939.) 24s. net.

$\mathrm{W}$ HEN a book such as this has reached its third edition it may be taken for granted that it possesses in high measure those qualities which go to the making of a standard work. Progress in heat engines. during recent years has been considerable, but provided the method of exposition of the fundamental principles is sound and the attitude of the author to his subject is a correct one, the main structure of the work will readily carry such new developments, either in theory or in practice, as take place between one edition and another. To this category then it may be said that the present book belongs, for while in large measure keeping pace with progress in heatpower engineering it retains the excellent mode of presentation which has characterized its earlier editions.

Some developments, however, have not received the attention they deserve. In the chapter on steam generators, mention is made of high pressure and of critical pressure steam generation, but there is no reference to the La Mont and Loeffler boilers, which are now fully established types. Their respective principles of operation and details of construction are essential to the present-day student of steam power, to which it may be said that the book gives a disproportionately large space.

Dealing first with general principles, the authors pass on to describe and elucidate the extensive range of equipment which goes to form a complete steam plant. Feed-water, its treatment and heating, chimneys, draught and fans, reciprocating engines and turbines, condensers and pumps are adequately dealt with, and there is a useful chapter on steam-engine power and economy.

Air compression, compressors and engines receive treatment compatible with the importance of the use of air as a source of power in such special cases as in deep mines, where it gives three advantages -its transmission for long distances without great loss, the cooling effect of its exhaust and its help in ventilation. It can scarcely be said, however, that the internal combustion engine has been dealt with as fully as its importance and variety deserve. Apart, however, from this criticism it should be pointed out that the theoretical and practical aspects of this section of the subject have been excellently presented, and the student will receive a good grounding, particularly in the fuels available and their combustion. 